sehr wünschenswerth, z. B. bei Turdus migratorius und Carpodacus erythrinus. Namentlich von letzterem die Beobachtung in Schwerin unter einem Flug von Pyrrhula rubicilla. Bisher wurde der Karmingimpel nur einzeln oder paarweise und gewöhnlich im Sommer beobachtet.

Erfreulich ist das Resultat des ersten Beobachtungsjahres immerhin. Es bringt eine Menge hochinteressanter Thatsachen und lässt uns hoffen, dass der gutnstige Erfolg bei wachsender Theilnahme sich mehr und mehr herausstellen wird. Namentlich wird es sich auch zeigen, dass viele Vögel lange nicht so selten sind, als man dies - bei der bisherigen unzureichenden Beobachtung - zu glauben geneigt ist.

E. F. v. Homeyer.

\title{
Catalogue of the Birds in the British Museum.
}

By R. B. Sharpe. Vol. I- III. London $187 \pm-77$.

Das "Ornithologische Centralblatt" hat bereits im Jahrg. 1877, No. 21, eine darauf bezügliche Anzeige gebracht. Die.grosse Nützlichkeit dieses descriptiven Catalogs macht es uns zur Pflicht, auch die Leser des Journals in Kürze auf die Vorzüge dieses hervorragend wichtigen Werkes hinzuweisen. G. R. Gray's „HandList" befindet sich ais ein unentbehrliches Hülfsmittel in den Händen wohl jedes Ornithologen, obgleich die Kargheit der Citate und der gänzliche Mangel einer Diagnose die Benutzung beeinträchtigte. Man beklagte die Kürze - aber dennoch blieb die "Hand-List" unentbehrlich. Um so unentbehrlicher wird Sharpe's Catalogue werden, da derselbe als eine neue, umfassend erweiterte und allen Ansprüchen geutigende Ausgabe zu betrachten ist. Eine surgfältige, fast erschöpfende Synomie, sowie ausfuhrliche Beschreibungen aller bis heut bekannten Arten, werlen aus der fruheren "Liste" ein $\mathrm{Handbuch}$ der speciellen Ornithologie machen.

Eine vollständige Synopsis Avium, der sehnliche Wunseh aller, welche sich mit Ornithologie beschüftigen, ist bisher ein pium desiderium geblieben. In London wirken die günstigsten Umstände zusammen und sind Bürgschaft für die in der kurzen Vorrede des Werkes ausgesprochene schnelle Fortfübrung und glückliche Vollendung des Ganzen. Letzteres ist und bleibt die Hauptsache! Dank dem Eifer und den umsichtigen Bemühungen der Direction des British Museum, Dank der uneruüdlichen Arbeitskraft des strebsamen Verfassers - das pium desiderium aller Ornithologen wird diesmal hoffentlich nicht zu Schanden werden. Wünschen wir daher dem überaus nützlichen Unternehmen einen ungestörten Fortgang.

Berlin, im Januar 1878.

Prof. Dr. J. Cabanis. 